\title{
DETERMINING THE CYCLIC STRENGTH OF GEOMATERIALS UNDER LOW FREQUENCY CYCLIC LOADING WITH ACOUSTIC EMISSION
}

\author{
Helsin Wang \\ Department of Construction Engineering, National Taiwan University of Science and Technology (Taiwan Tech), \\ Taipei, Taiwan, R.O.C, hswang@mail.ntust.edu.tw \\ Ta-Peng Chang \\ Department of Construction Engineering, National Taiwan University of Science and Technology (Taiwan Tech), \\ Taipei, Taiwan, R.O.C \\ Ju-Jiang Hung \\ Department of Civil and Environmental Engineering, National Taiwan University, Taipei, Taiwan, R.O.C
}

Follow this and additional works at: https://jmstt.ntou.edu.tw/journal

Part of the Civil and Environmental Engineering Commons

\author{
Recommended Citation \\ Wang, Helsin; Chang, Ta-Peng; and Hung, Ju-Jiang (2010) "DETERMINING THE CYCLIC STRENGTH OF \\ GEOMATERIALS UNDER LOW FREQUENCY CYCLIC LOADING WITH ACOUSTIC EMISSION," Journal of Marine Science \\ and Technology. Vol. 18: Iss. 6, Article 8. \\ DOI: $10.51400 / 2709-6998.1942$ \\ Available at: https://jmstt.ntou.edu.tw/journal/vol18/iss6/8 \\ This Research Article is brought to you for free and open access by Journal of Marine Science and Technology. It has been \\ accepted for inclusion in Journal of Marine Science and Technology by an authorized editor of Journal of Marine Science and \\ Technology.
}




\title{
DETERMINING THE CYCLIC STRENGTH OF GEOMATERIALS UNDER LOW FREQUENCY CYCLIC LOADING WITH ACOUSTIC EMISSION
}

\author{
Helsin Wang*, Ta-Peng Chang*, and Ju-Jiang Hung**
}

Key words: microcracking, acoustic emission, accelerative cracking point, cyclic loading.

\begin{abstract}
Acoustic emission is traditionally regarded as an explicit measurable index for microcracking in geomaterials. An accelerative cracking point is first introduced based on the different characteristics of acoustic emission at stable fracture propagation stage. Accelerative cracking point is located between the fracture initiation strength and critical energy release point, a point causing a fatal uncontrolled fracture in materials. Microcracking dominates the real mechanical characteristics in the materials, not reflected on the conventional mechanical experimental results as the stress level beyond the accelerative cracking point at the stable fracture propagation stage. At this stage, non-stress-controlled fracture in materials could arise as that found at unstable fracture propagation stage. Stress-releasing time experiments are also performed for time-dependent concerns. For the stress level equal or beyond fracture initiation strength of materials, the onset stress level gradually decreases below the previous maximum stress level as stress-releasing time increases.
\end{abstract}

\section{INTRODUCTION}

Acoustic emission is traditionally regarded as an explicit measurable index for microcracking in geomaterials. An accelerative cracking point is first introduced based on the different characteristics of acoustic emission at stable fracture propagation stage. Accelerative cracking point is located between the fracture initiation strength and critical energy release point, a point causing a fatal uncontrolled fracture in materials. Microcracking dominates the real mechanical char-

Paper submitted 11/20/08; revised 11/03/09; accepted 11/05/09. Author for correspondence: Helsin Wang (e-mail: hswang@mail.ntust.edu.tw).

*Department of Construction Engineering, National Taiwan University of Science and Technology (Taiwan Tech), Taipei, Taiwan, R.O.C.

**Department of Civil and Environmental Engineering, National Taiwan University, Taipei, Taiwan, R.O.C. acteristics in the materials, not reflected on the conventional mechanical experimental results as the stress level beyond the accelerative cracking point at the stable fracture propagation stage. At this stage, non-stress-controlled fracture in materials could arise as that found at unstable fracture propagation stage. Stress-releasing time experiments are also performed for time-dependent concerns. For the stress level equal or beyond fracture initiation strength of materials, the onset stress level gradually decreases below the previous maximum stress level as stress-releasing time increases.

Concrete and rocks are the most popular engineering materials attributed to brittle geomaterials besides steel. Many microcracks existing in geomaterials affect the mechanical behavior. The released elastic waves of damage in stressed materials are named as acoustic emission (AE) signals. AE signals are recognized as an efficient index highly related to microcracking in geomaterials. Analyzing the measured AE signals can directly know the damage in materials [10, 24, 32, 34]. An informative combination between AE signal characteristics and conventional macro-mechanical experimental results can elevate the accuracy of the mechanical properties in geomaterials.

During cyclic loading testing with loading-unloadingreloading type, AE signals are measured in stressed materials after reloading stress excesses its previous maximum stress level. The Kaiser effect of AE is positively confirmed, as the onset stress is equal to its previous maximum stress level. Due to microcrack closure, the criterion of Kaiser effect in geomaterials is defined as the onset stress of a large amount of AE signals during compression. The onset stress is not necessary the same as its previous maximum stress level [12, 17, 18, 22, 23, 35].

Lavrov [24] reports a review about the certain restrictions on the existence of the Kaiser effect. A well-pronounced Kaiser effect is sensitive to rock type and stress level (previous maximum stress to its ultimate strength). In brittle rocks, the Kaiser effect is best-pronounced when the stress level does not exceed the dilatancy stress value. In ductile rocks, the Kaiser effect always exists both before and after the dilatancy stress value. The closer the previous maximum stress to its ultimate 
strength, the less less-pronounced the Kaiser effect (inefficacy with Kaiser effect) is in brittle rocks. The Kaiser effect moves to lower stresses. It is quantitatively described as the felicity ratio (FR), an index defined as the ratio of $\mathrm{AE}$ onset stress to the previous maximum stress. Lavrov [24] points out that the previous maximum stress ranging about $30 \%$ to $80 \%$ of the ultimate strength can obtain a well-pronounced Kaiser effect. Some studies turn out that fracture initiation may be regarded as the stress level of inefficacy with Kaiser effect [4, 6, 11, 42].

This research investigates the changes of microcracking based on $\mathrm{AE}$ and mechanical experiments within the stress range of inefficacy with Kaiser effect. The effect of timedependent behavior on the Kaiser effect is also obtained from stress-releasing time experiments. For excluding the effect of heterogeneity in geomaterials, modeling material is used to replace real geomaterials in this research.

\section{RELATED RESEARCHES}

Many researchers suggest that the failure process can be divided into four sections in geomaterials under uniaxial compression $[2,4,6,11,15,28,39,42]$. The typical sections of a uniaxial compressive stress-strain curve in geomaterials are shown in Fig. 1. Points O, A, B, C, and D are stress initial, closure, fracture initiation, critical energy release, and strength failure, respectively. Crack closure stage (OA) represents that microcrack closure in rocks induces AE signals. During elastic deformation stage $(\mathrm{AB})$, the deformation of mineral crystals in geomaterials sustains the external loading. Few AE signals apparently indicate the decrease of stretch of existing microcracks in the material. During stable fracture propagation stage (BC), the existing microcracks start to extend from their corners. Nonlinear axial and volumetric deformations are measured and AE hit increases rapidly. When stress level enters the unstable fracture propagation stage (CD), these existing microcracks continuously elongate and new induced microcracks cause the increasing density of microcracks in geomaterials. Volumetric strain expands instead and highenergy-level AE signals suddenly increase. These physical characteristics last until strength failure (D). Generally speaking, fracture initiation (B) is around 30 to $35 \%$ of strength failure (D) and critical energy release (C) is around 75 to $80 \%$ of strength failure (D) $[2,6,15,28,42]$.

Holcomb [19] started to apply the concept of microcracking to the AE study in rocks. Complete stress-strain curves were simulated by modifying the modulus of deformation based on AE information in rocks $[7,8,20,25,26]$. The Kaiser effect of AE typically represents new microcracking [20]. Some AE signals are sometimes induced by microcrack closure instead of crack growth [20]. For rocks under different confining pressures, Li and Nordlund [26] measured the onset stress of AE signals is consistent with the previous maximum stress. The macro-mechanical behavior measured by conventional techniques is the total effect from the responses of material itself and the equivalent crack under loading. The interpreta-

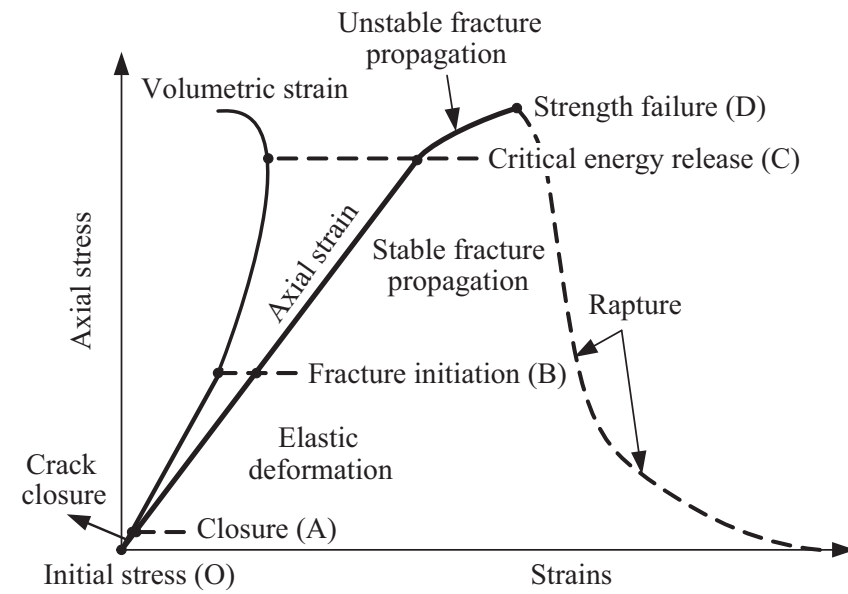

Fig. 1. Schematic of sections of the uniaxial compressive stress-strain curve in geomaterials.

tion of the uniaxial compressive stress-strain curves in geomaterials is described as the following:

1. The axial deformation is contributed by the closure of cracks at the initial loading.

2. The total deformation of different minerals in materials, not cracks, comprises the macroscopic deformation during elastic deformation stage $(\mathrm{AB})$.

3. When the stress level touches fracture initiation (B), new cracks are formed from the tips of existing microcracks and start to extend to the direction parallel to the direction of the principle stresses. The axial deformation comes from the fracture propagation and inner-face sliding of cracks during stable fracture propagation stage (BC). The propagation of stress-controlled fracture determines the macroscopic deformation in materials. The energy comes from the release of surface energy, sliding, and friction around cracks [38]. For the stress level below the critical energy release point (C), the kinetics energy can be ignored due to a lower crack growth velocity [2].

4. When the stress level increases to the critical energy release point (C), kinetic energy from a high crack growth velocity, inner-face friction resistance of microcracks, continuous extension from microcrack tips, and the increase and linkage of microcracks induce lateral deformation and swelling volumetric stain. Non-stress-controlled fracture in materials arises at the unstable fracture propagation section. The kinetic energy with a high crack growth velocity provides enough energy for the increase and linkage of microcracks even holding the stress level [2]. The crack growth velocity rapidly increases and continues to approach the terminal velocity at the strength failure (D).

When rocks under low cyclic loading, the AE hit representing the inner microscopic changes has a consistent macroscopic deformation in rocks [16]. A great amount of AE signals and the largest permanent deformation are observed at 


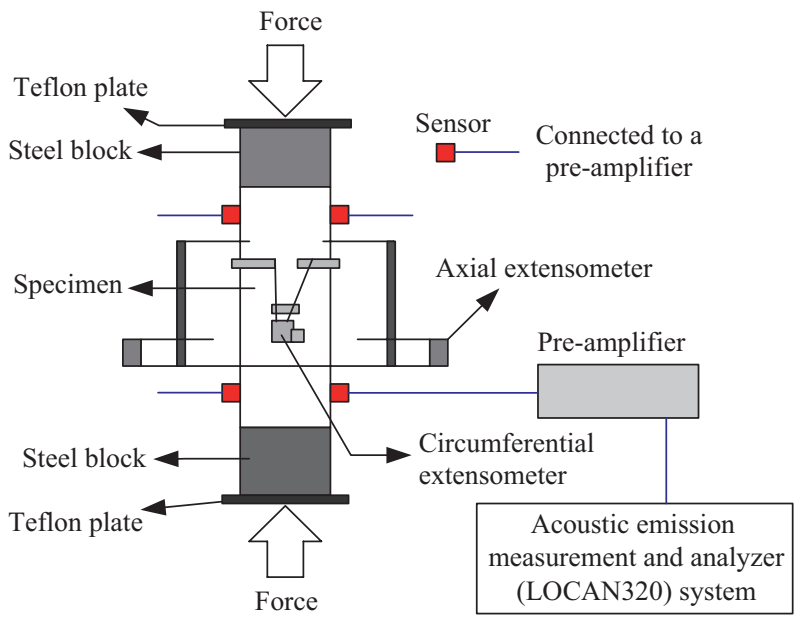

Fig. 2. Arrangement schematic of acoustic emission experiment.

the first cyclic loading. Both AE signals and corresponding deformation dramatically decrease in the subsequent cyclic loadings [38, 40-42]. At the loading stage, material itself and crack propagation/sliding balance the external loading energy. At unloading stage, the inner-face friction resistance and sliding of microcracks successively dominate the mechanical behavior in geomaterials [38].

The effect of stress-releasing time on the Kaiser effect has been discussed in geomaterials for years. Most of researchers conclude insignificant effect of stress-releasing time on the Kaiser effect [12, 17, 23, 26, 33, 35, 41]. Some other researchers, however, found that the onset stress level of $\mathrm{AE}$ signals gradually becomes lower than the previous maximum stress level as stress-releasing time increases. The onset stress level approaches a constant value after 10-day stress release [14, 29-31]. Stress-releasing time influence the existence of the Kaiser effect. Considering the close relationship between Kaiser effect and the maximum stress level can efficiently identify the effect of stress-releasing time on the Kaiser effect.

\section{ACOUSTIC EMISSION EXPERIMENTAL PLANS}

\section{Equipments and Experimental Procedure}

Figure 2 shows the arrangement of acoustic emission experiments. The equipments are (1) Physical Acoustics Cooperation (PAC) AE measurement and analyzer system, type LOCAN320, including a personal computer, post-amplifier, and signal processor in program L320loc environment for the measurement, storage, display, and analysis of acoustic emission signals, (2) AE sensor, type PAC NANO-30, tied to cylindrical specimens with tapes to measure AE signals, (3) Pre-amplifier, type PAC 1220, with a filter frequency range of 100 to $500 \mathrm{kHz}$, (4) 450-ton servo-control loading system, type MTS 315.03A-01, and (5) Deformation measurement system, including axial extensometer, type MTS-632.94C-20, and circumferential extensometer, type MTS-632.92C-05.
Table 1. Stress section points of the uniaxial compressive stress-strain curve in modeling material.

\begin{tabular}{|l|l|}
\hline \multicolumn{1}{|c|}{ Section point } & \multicolumn{1}{c|}{ Stress level } \\
\hline Crack closure point (A) & $0.98 \mathrm{MPa}(10 \mathrm{ksc})$ \\
\hline Fracture initiation (B) & $3.43-4.41 \mathrm{MPa}(35-45 \mathrm{ksc})$ \\
\hline Critical energy release (C) & $9.81-10.79 \mathrm{MPa}(100-110 \mathrm{ksc})$ \\
\hline Strength failure (D) & $15.4-15.99 \mathrm{MPa}(157-162 \mathrm{ksc})$ \\
\hline
\end{tabular}

Table 2. Basic mechanical properties of modeling material.

\begin{tabular}{|c|c|c|c|c|c|}
\hline $\begin{array}{c}\text { Mechanical } \\
\text { properties }\end{array}$ & $\begin{array}{c}\text { Compressive } \\
\text { strength }\end{array}$ & $\begin{array}{c}\text { Modulus of } \\
\text { deformation }\end{array}$ & $\begin{array}{c}\text { Tensile } \\
\text { strength }\end{array}$ & $\begin{array}{c}\text { Poisson's } \\
\text { ratio }\end{array}$ & $\begin{array}{c}\text { Bulk } \\
\text { density }\end{array}$ \\
\hline Values & $15.64 \mathrm{MPa}$ & $3.99 \mathrm{GPa}$ & $1.21 \mathrm{MPa}$ & 0.25 & $1.22 \mathrm{~g} / \mathrm{cm}^{3}$ \\
\hline
\end{tabular}

Table 3. Non-dimensional items in modeling material, real rocks, and normal concrete.

\begin{tabular}{|l|c|c|c|}
\hline $\begin{array}{c}\text { Dimensionless } \\
\text { items }\end{array}$ & $\begin{array}{c}\text { Modeling } \\
\text { material }\end{array}$ & Real rocks & $\begin{array}{c}\text { Normal } \\
\text { concrete }\end{array}$ \\
\hline Modulus ratio & 255 & $50-1200$ & $240-1300$ \\
\hline Strength ratio & 12.93 & $>5$ & $>3$ \\
\hline Poisson's ratio & 0.25 & $0.11-0.5$ & $0.1-0.3$ \\
\hline
\end{tabular}

The modeling geomaterial is a harden mixture of water and gypsum with water-to-gypsum ratio 0.58 in weight at room temperature in laboratory. The modeling geomaterial is attributed to a brittle type geomaterial since a steep stress decrease in its stress-strain curve, similar to Fig. 1, is found after its strength failure. The stress section points of its stress-strain curve are listed in Table 1. The dimension of cylindrical specimens is $100 \mathrm{~mm}$ in diameter and $200 \mathrm{~mm}$ in length. The basic mechanical properties of the modeling material are shown in Table 2. Three main dimensionless items, modulus ratio (modulus of deformation/shear modulus), strength ratio (compressive strength/tensile strength), and Poisson's ratio, of modeling material, real rocks, and normal concrete are listed in Table $3[9,13,26,27,36]$. The dimensionless values of the modeling material are located within the reasonable ranges of real rocks and normal concrete.

To measure weak AE signals in modeling material, a total factor of magnification in decibel $(\mathrm{dB})$ is used as $80 \mathrm{~dB}$, including $20 \mathrm{~dB}$ in the pre-amplifier and $60 \mathrm{~dB}$ in the postamplifier. Five (5) noise sources, including contact sensitivity of sensors, background noise, micro-vibration during loading, collateral vibration between sensor wires and pre-amplifiers, and boundary conditions on the two ends of cylindrical specimens of are eliminated in acoustic emission experiments. The measurement frequency range and $\mathrm{AE}$ signal parameters are also set in control program L320loc. The experimental procedures to treat signal noise and program parameters are described in the following in detail.

(1) Pensile test: Breaking a pensile lead on a specimen surface 
Table 4. Stress-releasing time experiments in modeling material.

\begin{tabular}{|l|c|}
\hline \multicolumn{1}{|c|}{ Maximum stress level } & Stress-releasing time (Days) \\
\hline $1.96 \mathrm{MPa}(20 \mathrm{ksc})$ & $0,32,64$ \\
\hline $\begin{array}{l}3.92 \mathrm{MPa}(40 \mathrm{ksc}) ; 6.87 \mathrm{MPa} \\
(70 \mathrm{ksc}) ; 8.83 \mathrm{MPa}(90 \mathrm{ksc})\end{array}$ & $0,16,32$ \\
\hline
\end{tabular}

simulates cracking in a solid material and using three or more sensors can localize this pseudo-acoustic emission signal source. The purpose of pensile tests used in this research addresses on the check-up of contact sensitivity conditions of five sensors by observing the sensitivity of measured signals.

(2) Background noise check-up test: The program threshold amplitude/energy of $43 \mathrm{~dB}$ can fully eliminate the effect from the background noise.

(3) Micro-vibration check-up test during loading: The program threshold amplitude/energy of $45 \mathrm{~dB}$ can fully eliminate the micro-vibration effect during loading.

(4) Collateral vibration check-up test: The extra noises are observed in sensor wires and pre-amplifiers due to collateral vibration. The threshold amplitude/energy of 45 to $55 \mathrm{~dB}$ is located within the main amplitude/energy of modeling materials during cracking. The treatment to fix sensor wires and pre-amplifiers are operated against such vibrations.

(5) Program frequency test: Program frequency range is chosen between 100 and $490 \mathrm{kHz}$ for the resonant frequency ranges in modeling materials and sensors.

(6) Program parameter setting test: Using pensile tests to localize an acoustic emission event can determine a proper peak definition time (PDT), hit definition time (HDT), and hit lockout time (HLT) in program parameter setting. The PDT, HDT, and HLT used in modeling materials are $20 \mathrm{sec}, 40 \mathrm{sec}$, and $110 \mathrm{sec}$, respectively.

(7) Boundary conditions on the two ends of specimens: Using Teflon plates as buffers between a specimen and the loading system can efficiently lower the friction noise and boundary binding effect.

\section{Acoustic Emission Experiments}

This research follows relevant testing methods for uniaxial compression recommended by International Society for Rock Mechanics (ISRM) and American Society for Testing and Materials (ASTM) [1, 3]. The changes of microcracking in modeling geomaterial can be interpreted based on the acoustic emission characteristics. Two main acoustic emission experiments are described as below:

1. Cyclic loading acoustic emission experiments with different stress levels: Four (4) different maximum stress levels, $3.92 \mathrm{MPa}(40 \mathrm{ksc}), 6.87 \mathrm{MPa}(70 \mathrm{ksc}), 8.83 \mathrm{MPa}(90 \mathrm{ksc})$, and $11.77 \mathrm{MPa}(120 \mathrm{ksc})$, are chosen for the cyclic loading experiments in 12 cylindrical specimens. Based on the stress section points of the uniaxial compressive stressstrain curve in modeling material as shown in Table 1, these 4 stress levels ranges the stress level from fracture initiation (B) to unstable fracture propagation stage (CD).

2. Stress-releasing time experiments: Stress-releasing time, ranging from 0 to 64 days, experiments listed in Table 4 are performed in 18 modeling material specimens first. The stress level of inefficacy with Kaiser effect is identified as the onset stress of numerous acoustic emission signals during monotonic uniaxial compression.

Based on the AE energy distribution in modeling material under uniaxial compression experiment, the low, middle, and high energy levels are below $48 \mathrm{~dB}$, between 49 and $52 \mathrm{~dB}$, and above $52 \mathrm{~dB}$, respectively.

\section{CYCLIC ACOUSTIC EMISSION EXPERIMENTS}

\section{Experimental Results and Analysis}

Figure 3 shows a typical cyclic loading AE experimental result with fracture initiation (B), $3.92 \mathrm{MPa}(40 \mathrm{ksc})$. The AE cumulative hit increases rapidly at the first few loadingunloading cycles. The AE cumulative hit increases slowly at the following cycles. At the first few loading-unloading cycles, a higher AE hit rate with low-to-high energy level is observed in Figs. 3(b) and 3(c). At the following cyclic loading, scattering low-energy-level AE signals occur at loading stage due to crack closure. Such an observation is consistent with relevant researches $[4,11,12,16,17,25,26,29-31$, 40-42]. This also indicates the existence of the Kaiser effect at fracture initiation (B).

Figure 4 shows a typical cyclic loading AE experimental result with stable fracture propagation stage (BC), 6.87 $\mathrm{MPa}$ $(70 \mathrm{ksc})$. The distribution of AE cumulative hit in step type consistently corresponds to the distribution of loadingunloading cycles. The increasing spire-like distribution of $\mathrm{AE}$ hit rate also corresponds to the distribution of loadingunloading cycles. The AE signals ranging from low to high energy level are observed at the first loading-unloading cycle. The low-energy-level AE signals repeatedly are measured at the following loading-unloading cycle. The AE onset stress occurs at around fracture initiation $(3.92 \mathrm{MPa})$ at subsequent cycles. Their FR values are around 0.6 at stable fracture propagation stage (BC). Such an observation is inconsistent with relevant researches [12, 16, 17, 26, 27, 30-32, 41, 42] for these studies report that no or few AE signals are found in the succeeding loading-reloading cycle. Figure 4 shows a typical cyclic loading AE experimental result with stable fracture propagation stage $(\mathrm{BC}), 6.87 \mathrm{MPa}(70 \mathrm{ksc})$. The distribution of AE cumulative hit in step type consistently corresponds to the distribution of loading-unloading cycles. The increasing spire-like distribution of $\mathrm{AE}$ hit rate also corresponds to the 


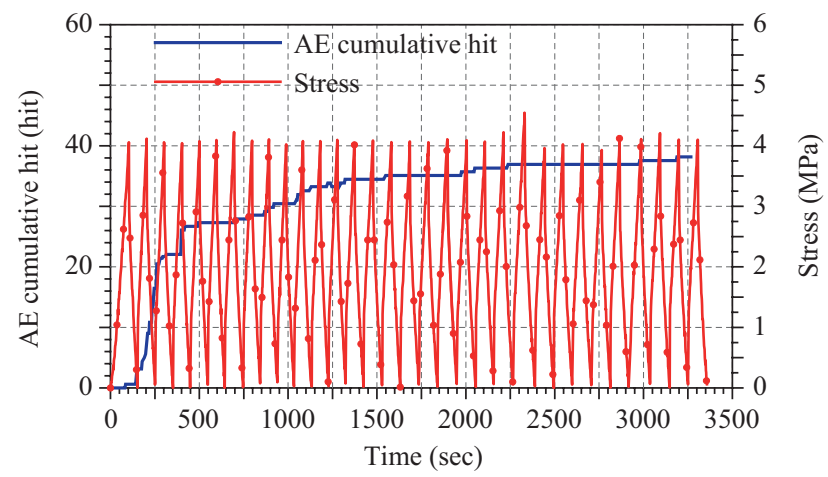

(a)

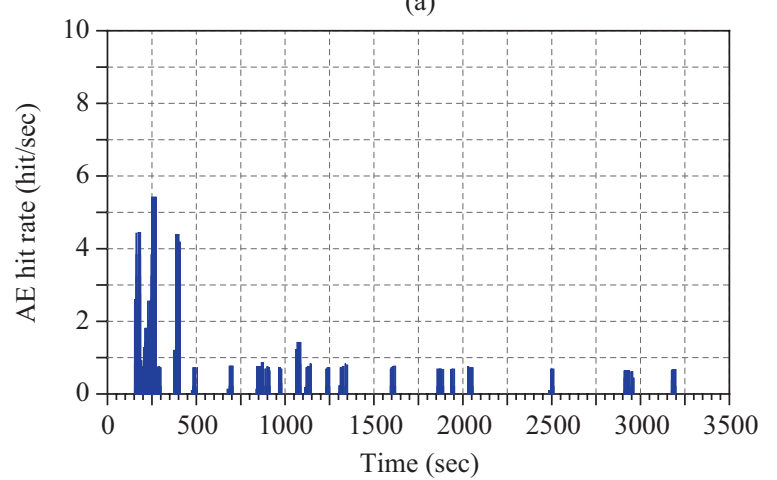

(b)

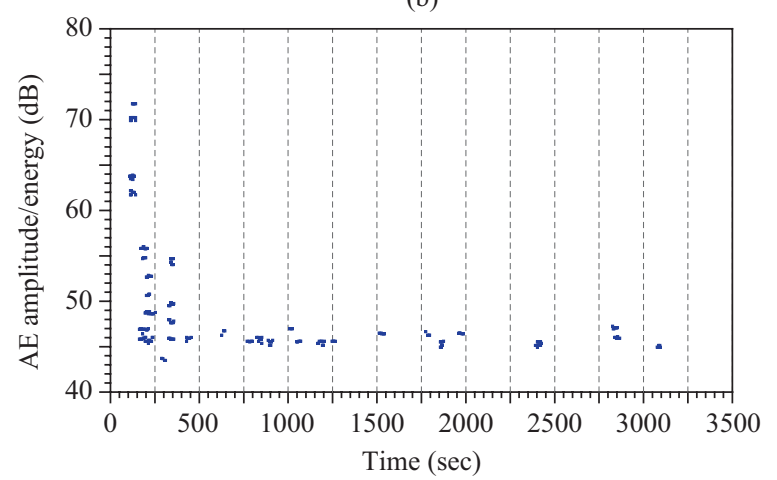

(c)

Fig. 3. Cyclic loading acoustic emission experiment with fracture initiation in modeling material: (a) acoustic emission cumulative hit and stress, (b) acoustic emission hit rate, and (c) acoustic emission amplitude/energy.

distribution of loading-unloading cycles. The AE signals ranging from low to high energy level are observed at the first loading-unloading cycle. The low-energy-level AE signals repeatedly are measured at the following loading-unloading cycle. The AE onset stress occurs at around fracture initiation (3.92 MPa) at subsequent cycles. Their FR values are around 0.6 at stable fracture propagation stage (BC). Such an observation is inconsistent with relevant researches $[12,16,17$, $26,27,30-32,41,42]$ for these studies report that no or few AE signals are found in the succeeding loading-reloading cycle.

At stable fracture propagation stage (BC), more detailed $\mathrm{AE}$ characteristics reveals the internal changes in the modeling

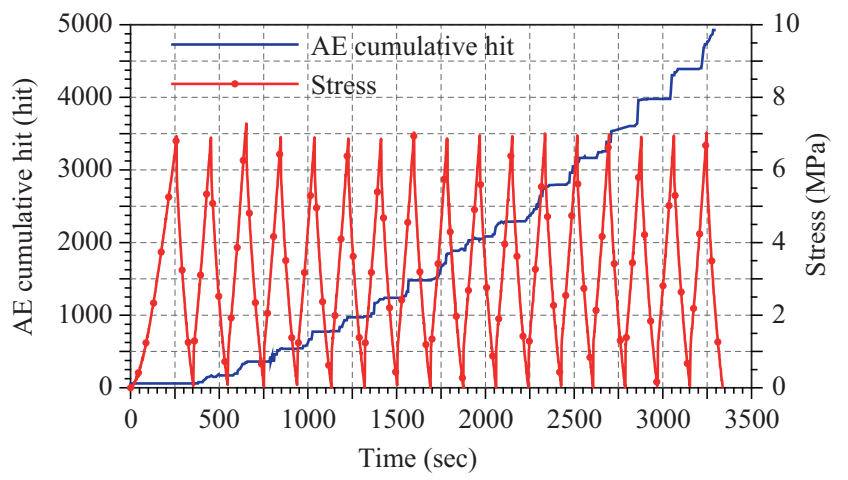

(a)

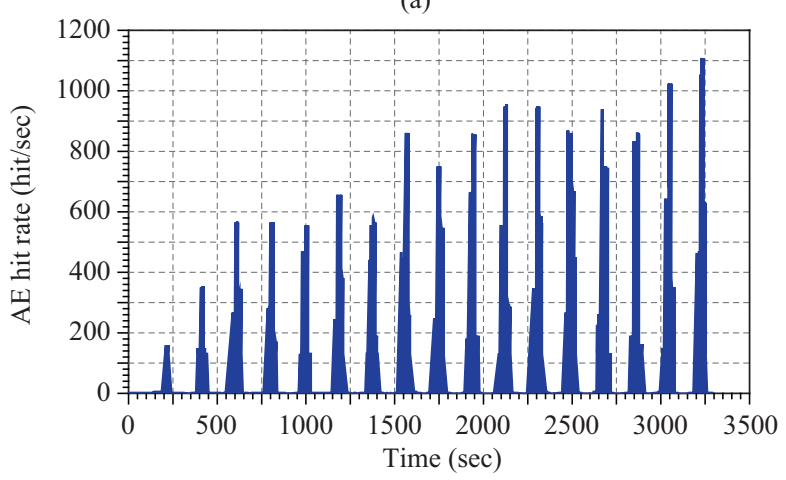

(b)

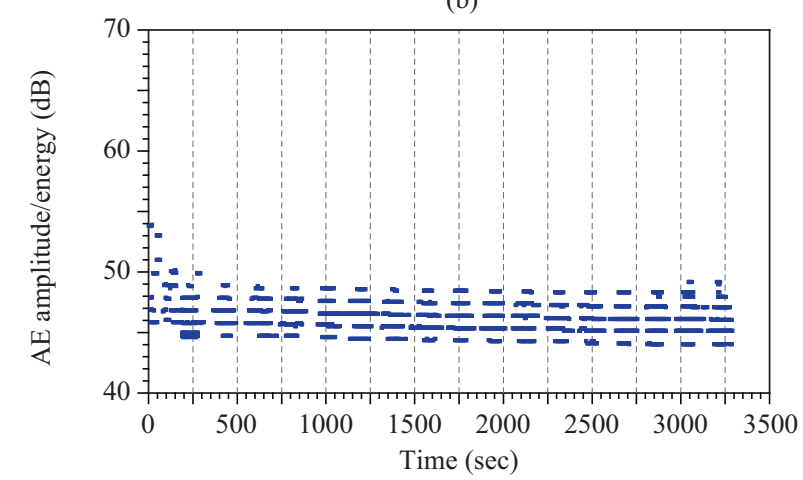

(c)

Fig. 4. Cyclic loading acoustic emission experiment with stable fracture propagation former section in modeling material: (a) acoustic emission cumulative hit and stress, (b) acoustic emission hit rate, and (c) acoustic emission amplitude/energy.

materials as the number of loading-unloading cycle increases. At the first few cycles, the highest $\mathrm{AE}$ hit rate happens at the loading stage, as shown in Fig. 5. Instead, the last few cycles, the highest AE hit rate occurs around the peak stress, as shown in Fig. 6. The corresponding first and last 6 cyclic axial and lateral stress-strain curves, as shown in Fig. 7, have no significant strain change. When the number of cycle increases, the micro-mechanical behavior truly changes due to the change of AE characteristics; however, its corresponding macromechanical measurement cannot reflect the internal changes in materials.

When the previous maximum stress level of the cyclic loading is set at $8.83 \mathrm{MPa}(90 \mathrm{ksc})$, still belonging to stable 


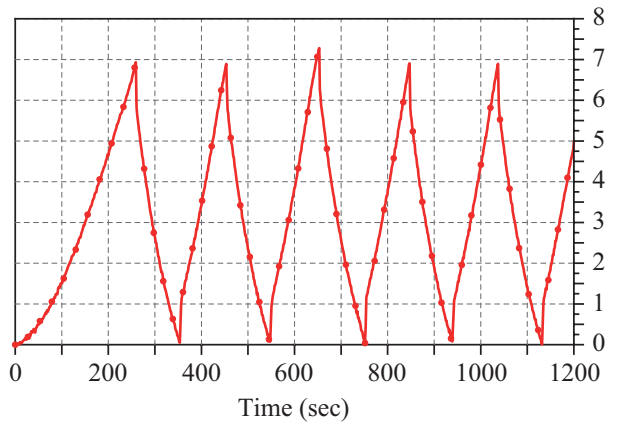

(a)

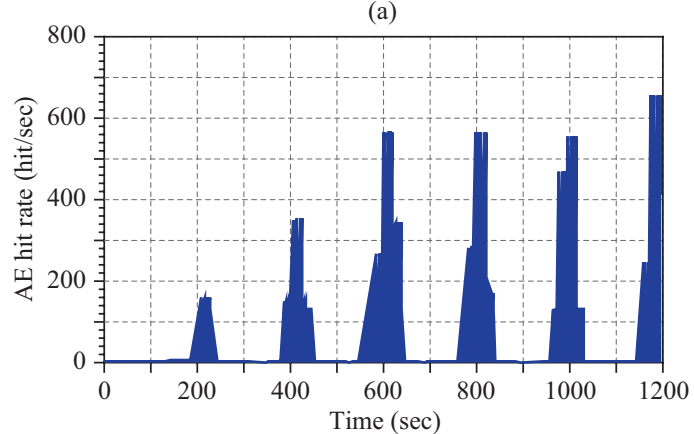

(b)

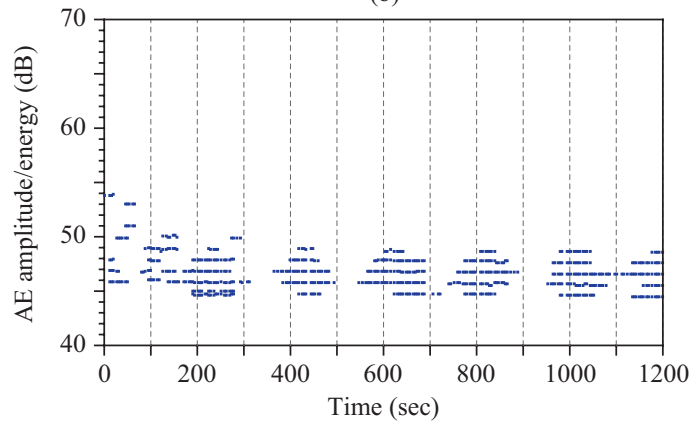

(c)

Fig. 5. Cyclic loading acoustic emission experiment with stable fracture propagation former section at first $\mathbf{6}$ cycles in modeling material: (a) stress, (b) acoustic emission hit rate, and (c) acoustic emission amplitude/energy.

fracture propagation stage (BC), the typical cyclic loading $\mathrm{AE}$ experimental results are shown in Fig. 8. At the first cycle, the energy of the AE hit rate ranges from low to high levels. At the subsequent cycles, the AE hit rate with low energy level will continuously increase as the number of loading-unloading cycle is increasing. The highest $\mathrm{AE}$ hit rate occurs at around the unloading stage. In addition, significant few AE signals with middle-to-high energy level indicated with arrows in Fig. 8 (c) are detected at crack closure stage (OA). When reloading stresses, microcracks arise more severe closure activities at a higher previous maximum stress level $(8.83 \mathrm{MPa})$ than those at lower previous maximum stress levels $(1.96,3.92$, and 6.87 $\mathrm{MPa}$.

Figure 9 shows a typical cyclic loading AE experimental result at unstable fracture propagation stress level (CD), 11.77 $\mathrm{MPa}(120 \mathrm{ksc})$. The step-like distribution of AE cumulative hit increases and corresponds to the distribution of loading-

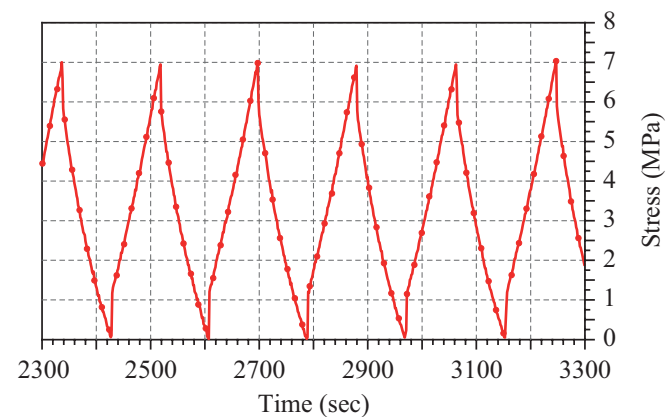

(a)

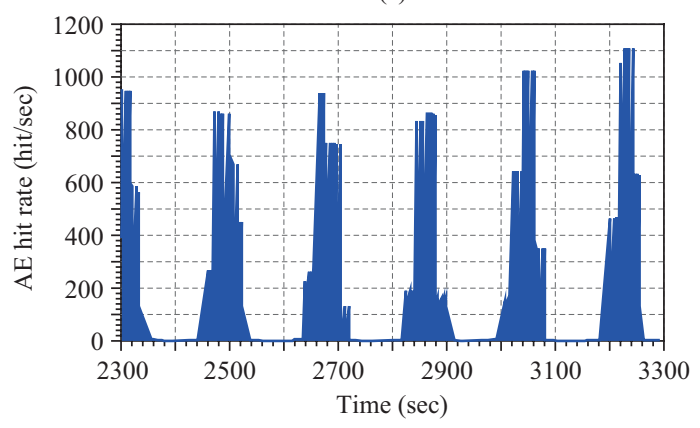

(b)

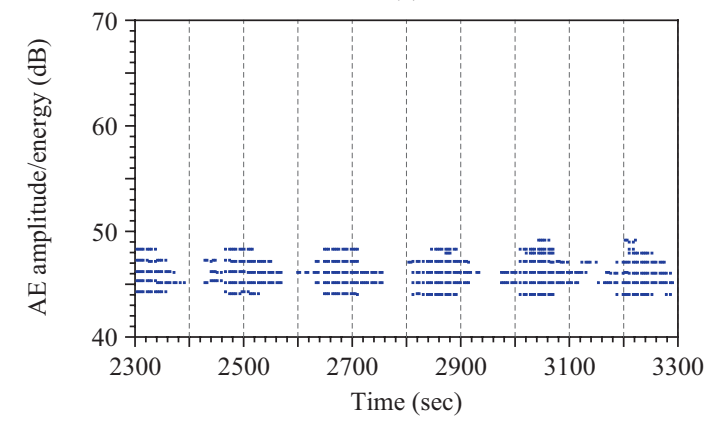

(c)

Fig. 6. Cyclic loading acoustic emission experiment with stable fracture propagation former section at last 6 cycles in modeling material: (a) stress, (b) acoustic emission hit rate, and (c) acoustic emission amplitude/energy.

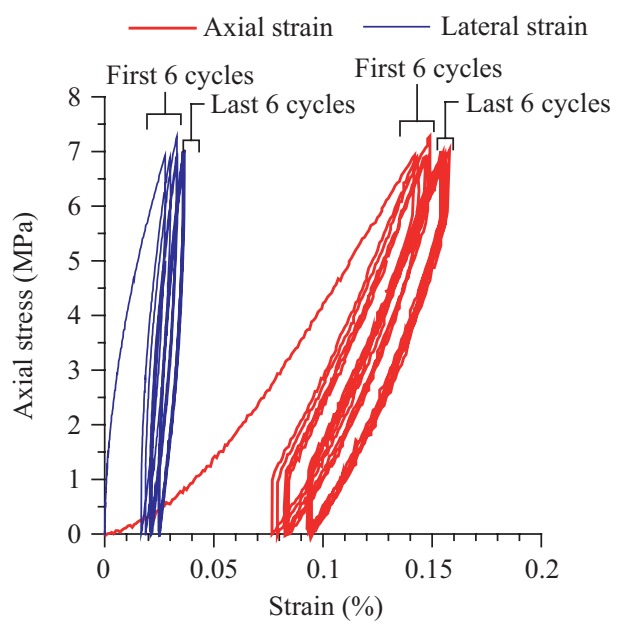

Fig. 7. First and last 6 cyclic stress-strain curves at stable fracture propagation former section. 


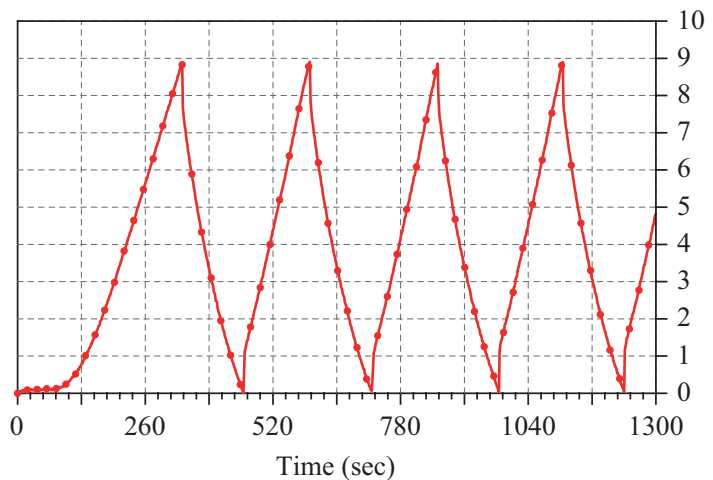

(a)

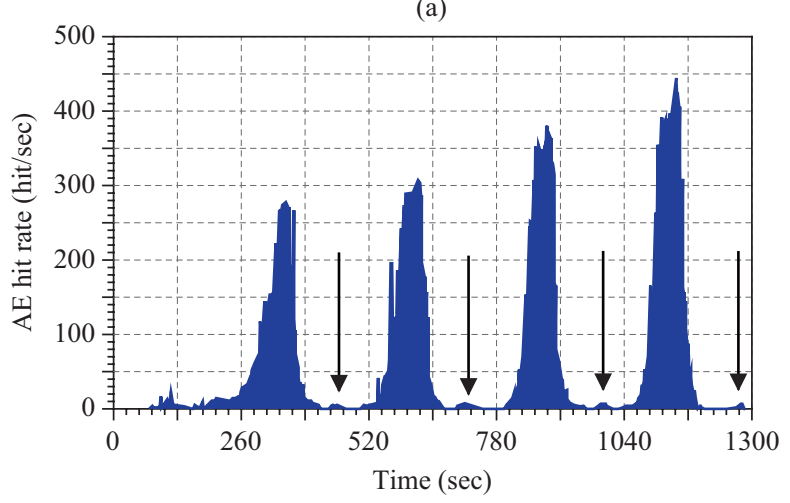

(b)

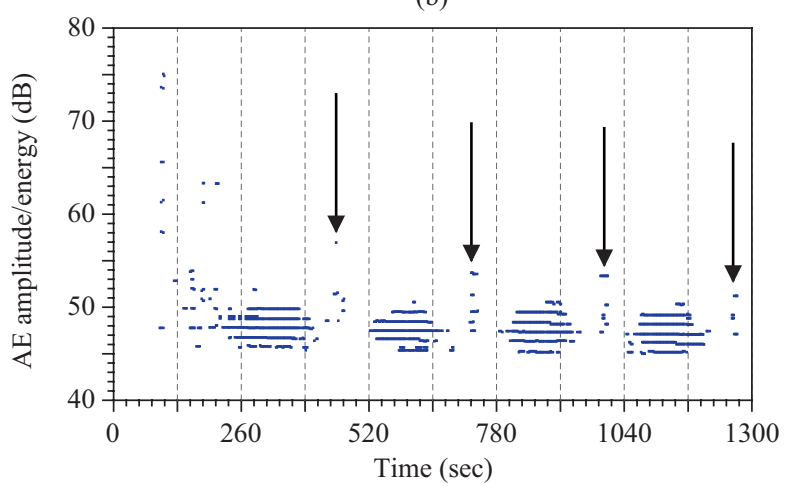

(c)

Fig. 8. Cyclic loading acoustic emission experiment with stable fracture propagation later section at first $\mathbf{4}$ cycles in modeling material: (a) stress, (b) acoustic emission hit rate, and (c) acoustic emission amplitude/energy.

unloading cycles. The continuously increasing spire-like distribution of $\mathrm{AE}$ hit rate corresponds to the distribution of loading-unloading cycles. At the first cycle, the energy of AE signals ranges from low to high levels. At the subsequent cycles, the AE signals with low energy level will continuously increase as the number of loading-unloading cycle is increasing. The highest AE hit rate occurs around the peak stress. The energy level distribution of AE signals is similar to that with stable fracture propagation stress level. In addition, a great amount of AE signals with low-to-high energy level (labeled as arrows in Fig. 9) indicate that microcracking, including inner-face friction, extension, and linkage of micro-

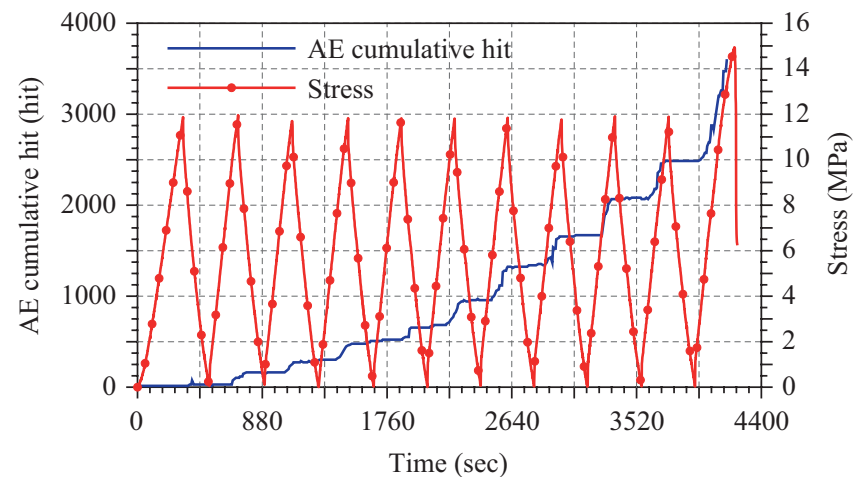

(a)

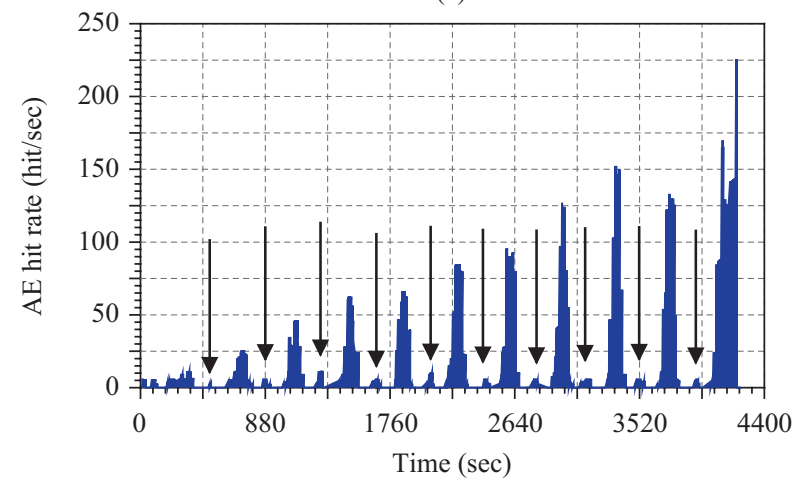

(b)

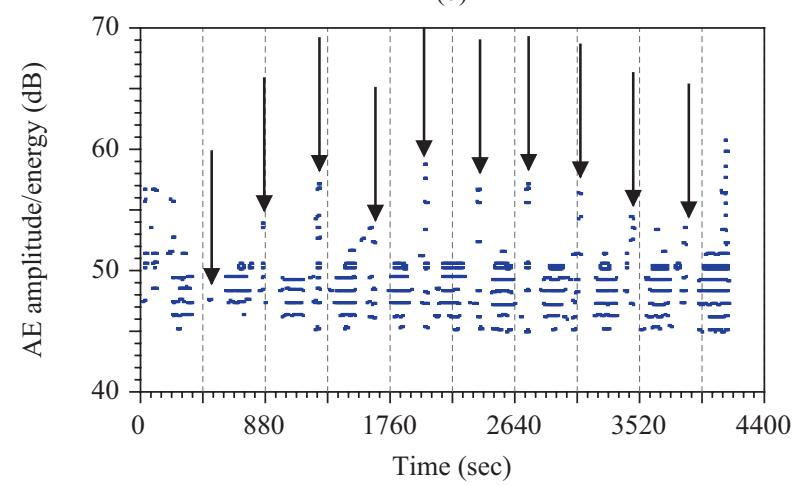

(c)

Fig. 9. Cyclic loading acoustic emission experiment with unstable fracture propagation section in modeling material: (a) acoustic emission cumulative hit and stress, (b) acoustic emission hit rate, and (c) acoustic emission amplitude/energy.

cracks can generate much more severe and complicate crack closure actions than those (few AE signals with medium-tohigh energy level) at a previous maximum stress level below the critical energy release point (C).

\section{Discussion on Microcracking}

Bieniawaki [2] theoretically developed and experimentally verified a microcrack model related to the four-section failure process in geomaterials under uniaxial compression in section II. This model describes such a failure process as a form in term of crack growth velocity and crack length, as shown in Fig. 10. An ultra-high speed camera is employed to measure 


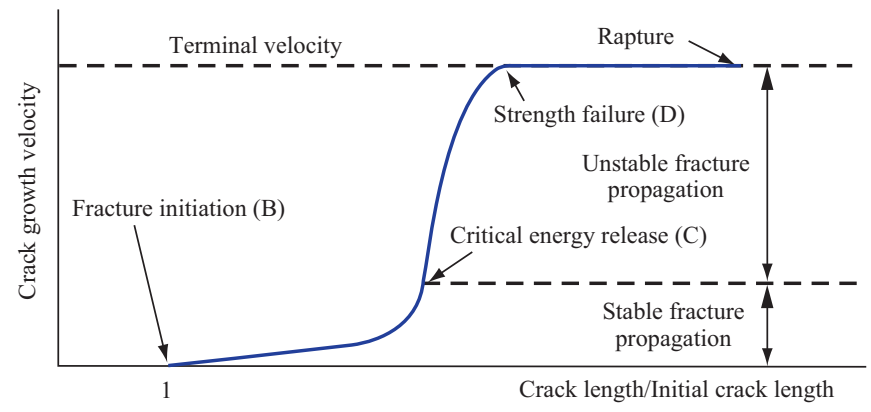

Fig. 10. Relationship between crack growth velocity and crack length (after [2]).

the crack growth velocity of rock under uniaxial stress. The crack growth velocity launches at fracture initiation (B) corresponding to the crack length to initial crack length ratio as one. During stable fracture propagation stage (BC), the elastic strain energy is totally transformed into crack surface energy inducing extension from microcrack tips. The amount of its kinetic energy expressed as crack growth velocity can be neglected during stable fracture propagation stage (BC). The fracture process is controlled by its loading level. After the turning point, critical energy release point $(\mathrm{C})$, the elastic strain energy is transformed into crack surface energy and kinetic energy. The kinetic energy becomes the governing factor in the process of unstable fracture propagation stage (CD). The fracture process becomes non-stress-controlled and self-maintaining in rocks. The terminal growth velocity is around 0.38 times of bar wave velocity at strength failure (D). The constant velocity is maintained during the stage of forking and coalescence of cracks until rock rapture.

In this research, there are two different AE characteristics found in these AE experiments with the previous everexperienced maximum stress falling within stable fracture propagation stage (BC) have been shown in Figs. 4 to 6 and 8 . When the previous maximum stress level of cyclic loading is below $7.85 \mathrm{MPa}(80 \mathrm{ksc})$, the highest $\mathrm{AE}$ hit rate occurs around loading stage. The highest AE hit rate shifts into the unloading stage as the number of loading-unloading cycle increases. The internal damage is also aggravated by increasing number of loading cycle. When the previous maximum stress level of the cyclic loading is above $7.85 \mathrm{MPa}(80 \mathrm{ksc})$, the highest AE hit rate and energy occur around the unloading stage. Some AE signals with middle-to-high energy level are measured at crack closure stage (OA). The AE characteristics altered with a specific stress level reflect some certain changes of microcracking at stable fracture propagation stage (BC). However, the uniaxial compressive stress-strain curve, shown in Fig. 11, remains similar hysteresis loops to those with a previous maximum stress level below $7.85 \mathrm{MPa}(80 \mathrm{ksc})$ shown in Fig. 7. Comprehensively, the changes of AE characteristics are different from the description, a stress-controlled state at stable fracture propagation stage $(\mathrm{BC})$, given by $\mathrm{Bi}-$ eniawaki's microcrack model [2] with a compressive stress-

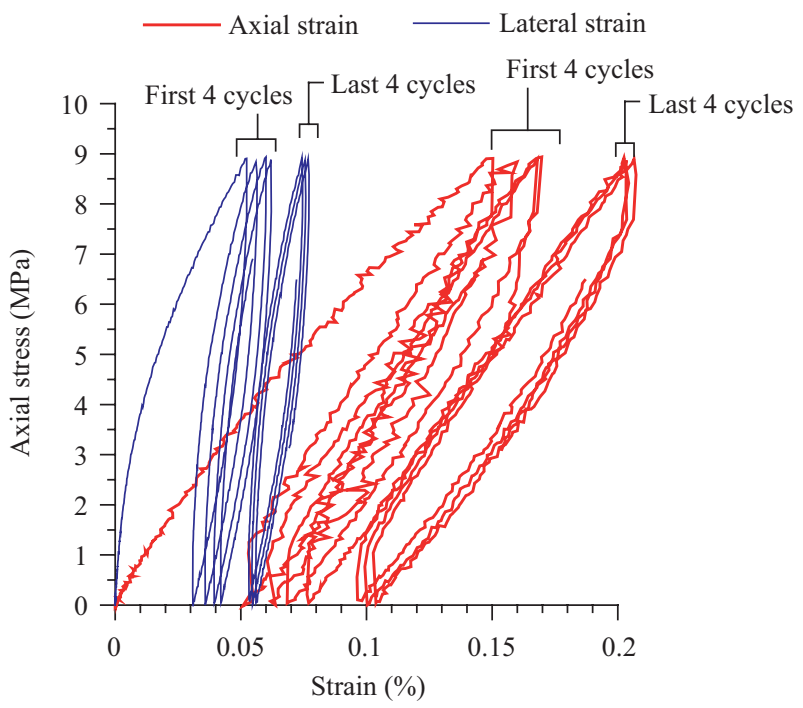

Fig. 11. First and last 4 cyclic stress-strain curves at stable fracture propagation later section.

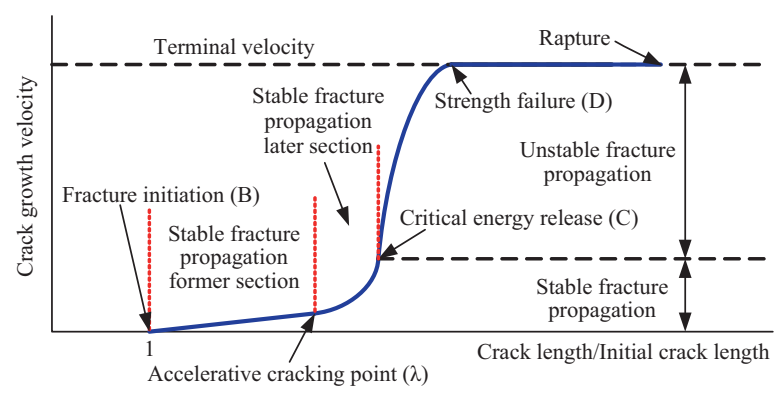

Fig. 12. Modified relationship between crack growth velocity and crack length (modified from [2]).

strain curve conventionally measured by macro-mechanical equipment.

Based on the changes of $\mathrm{AE}$ characteristics found at stable fracture propagation stage (BC), two subsections, stable fracture propagation former section $(\mathrm{B} \lambda)$ and stable fracture propagation later section $(\lambda C)$, are suggested herein at stable fracture propagation stage (BC). A division point, accelerative cracking point $(\lambda)$, is introduced between the fracture initiation strength (B) and critical energy release point (C). This point $(\lambda)$ is the turning point of the crack growth velocity changing from the gradual increase state into the steep increase state, as shown in Fig. 12. Comparing AE characteristics with crack growth velocity plot in Fig. 12, microcracking are interpreted as the following in detail:

1. The previous maximum stress level at stable fracture propagation stage $(\mathrm{BC})$ : A rapid increasing $\mathrm{AE}$ hit rate indicates that kinetic energy from an increasing crack growth velocity should not be completely ignored its effect, different from the conventional observation [2].

2. The previous maximum stress level during stable fracture 
Table 5. Results of Kaiser effect of stress-releasing time experiments in modeling material.

\begin{tabular}{|c|c|c|c|c|}
\hline Stress-releasing time (Days) & 0 & 16 & 32 \\
\hline Elastic deformation & $\mathrm{E}$ & $\mathrm{N} / \mathrm{T}$ & $\mathrm{E}$ \\
\hline Fracture initiation & $\mathrm{E}$ & $\mathrm{E}$ & $\mathrm{F}$ (Elastic deformation) & $\mathrm{N} / \mathrm{T}$ \\
\hline $\begin{array}{c}\text { Stable fracture propagation } \\
\text { (former section) }\end{array}$ & $\mathrm{F}$ (Fracture initiation) & $\mathrm{F}$ (Fracture initiation) & $\mathrm{F}$ (Elastic deformation) & $\mathrm{N} / \mathrm{T}$ \\
\hline $\begin{array}{c}\text { Stable fracture propagation } \\
\text { (later section) }\end{array}$ & $\mathrm{F}$ (Stable fracture propagation) & $\mathrm{F}$ (Elastic deformation) & $\mathrm{F}$ (Initial loading) & $\mathrm{N} / \mathrm{T}$ \\
\hline
\end{tabular}

Note 1: E, F, and N/T indicate existence, failure, and no testing, respectively.

Note 2: The onset stress ranges of a large amount of AE signals are shown in parentheses.

propagation former section $(\mathrm{B} \lambda)$ : The macro-mechanical behavior, including stress and strain, is consistent with its micro-mechanical behavior, i.e., AE activity. Even though minor AE signals imply microcracks with a wider opening and longer crack length, the kinetic energy of increasing crack growth velocity and inner-face friction resistance of microcracks still can be ignored. The minor AE signals reveal the occurrence of internal changes, but not are detected by strain measurement. The conventional mechanical experimental results can completely reflect the real mechanical characteristics in materials.

3 . Under the previous maximum stress level falling at stable fracture propagation later section $(\lambda \mathrm{C})$ :

(a) An extra kinetic energy from a sudden increase of crack growth velocity leads to the increases of microcracking and AE signals. Inner-face friction and continuous extension from microcrack tips during unloading stage induce higher $\mathrm{AE}$ hit rates than those at loading stage. AE signals with middle-to-high energy level are measured at crack closure stage (OA) due to more severe microcrack closure.

(b) AE activity continuously increases with the increase of number of loading-unloading cycle. This indicates that microcracking is no longer controlled by its stress level. AE activity provides critical inner changes similar to the non-stress-controlled facture occurring at unstable fracture propagation. When the number of loading cycle increases, the micro-mechanical behavior is similar to the stable fracture propagation former section $(\mathrm{B} \lambda)$. At the same time, a lack of significant changes can be found in conventional stress-strain curves. Microcracking dominates the real mechanical characteristics in stressed materials, not reflected on the conventional mechanical experimental results. Stress level close to the critical energy release point $(\mathrm{C})$ could lead to a non-stress-controlled fracture in materials.

4. Under the previous maximum stress level during unstable fracture propagation stage $(\mathrm{CD})$ : Kinetic energy with a high crack growth velocity, inner-face friction resistance of microcracks, continuous extension from microcrack tips, and increase and linkage of microcracks induce continuously increasing AE hit rate and a great amount of AE signals with low-to-high energy level during crack closure stage (OA). The changes of microcracking also affect a macro-level change in expanding volumetric strain measured by conventional mechanical techniques.

Beyond the stress level of inefficacy with Kaiser effect, stable fracture propagation stage (BC), the changes of microcracking are measured in AE experiments in modeling materials. Based on the experimental results, several points can be suggested at the engineering design stage. (1) An accelerative cracking point $(\lambda)$ is highly recommended at stable fracture propagation stage $(\mathrm{BC})$. The stable fracture propagation stage (BC) is divided into two subsections, stable fracture propagation former section $(\mathrm{B} \lambda)$ and stable fracture propagation later section $(\lambda \mathrm{C})$. (2) When using geomaterials as engineering materials, allowable design stresses are suggested below the accelerative cracking point $(\lambda)$, not the critical energy release point (C) for preventing from over-estimating the design strength obtained from the conventional mechanical tests. (3) A monitoring system is recommended for the long-term design when stresses approach the accelerative cracking point $(\lambda)$ in civil structures.

\section{STRESS-RELEASING TIME}

The results of stress-releasing time experiments are listed in Table 5. The relationship between felicity ratio (FR) and stress-releasing time with different previous maximum stress levels is plotted in Fig. 13. Generally, for the previous maximum stress level below fracture initiation (B), stress-releasing time has no effect on the Kaiser effect. For the previous maximum stress level equal to or higher than fracture initiation (B), the FR value is decreasing from 1 to 0.58 as stressreleasing time increases from 0 to 32 days. The onset stress level of AE signals becomes lower than the previous maximum stress level, the corresponding FR value below 1. Fracture initiation (B) is identified as the stress level of inefficacy with Kaiser effect. The onset stress level of AE signals decreases as stress-releasing time becomes longer. Such conclusions are consistent with relevant researches [14, 29-31].

The time-dependent behavior of microcracking in modeling geomaterials is described as the following: (1) During elastic deformation stage $(\mathrm{AB})$, the original length of microcracks is maintained since the deformation of mineral crystals contrib- 


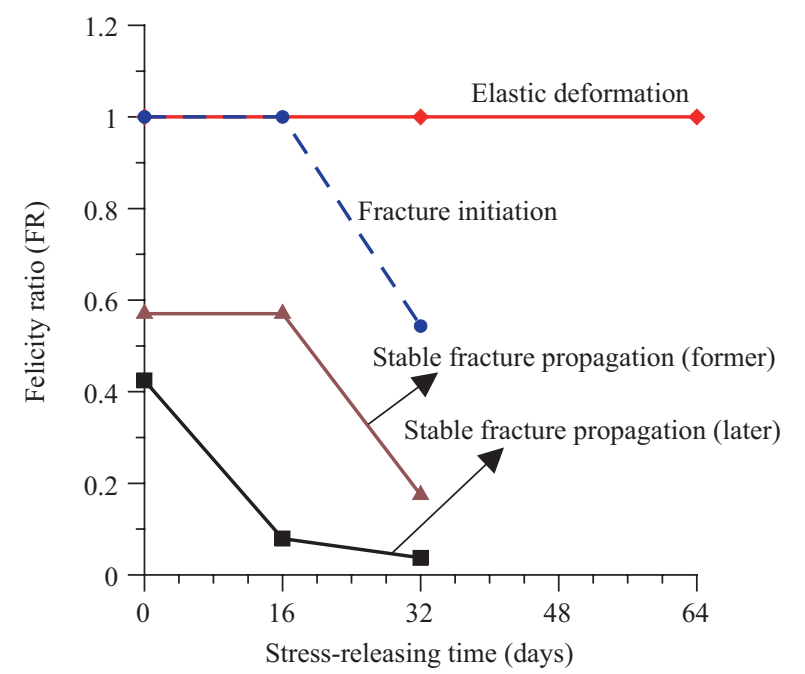

Fig. 13. Relationship between felicity ratio (FR) and stress-releasing time with different previous maximum stress levels.

utes the external deformation. The existence of the Kaiser effect is not affected by stress-releasing time. (2) When stress rises to fracture initiation (B), the mechanism of microcracking is triggered and extends to the direction of the maximum principle stress. The opening of microcracks gradually becomes wider as stress-releasing time increases from 0 to 32 days. Stress-releasing time starts to undermine the existence of the Kaiser effect. (3) When the stress level increases to stable fracture propagation former section $(\mathrm{B} \lambda)$, microcracks with wider opening cause the decrease of the onset stress level of AE signals from fracture initiation (B) into elastic deformation section $(\mathrm{AB})$ as stress-releasing time increases from 0 to 32 days. The Kaiser effect cannot be applied at the stress level beyond fracture initiation (B). (4) When the stress level is at stable fracture propagation later section $(\lambda C)$, a more number of longer microcracks with much wider opening result in the decreasing onset stress level of AE signals from fracture initiation (B) into the initial loading. The AE signals are induced by microcrack closure or inner-face friction of microcracks.

According to the stress-releasing time experiments, stressreleasing time should be taken into account during design stage in civil structures using geomaterials. To prevent from the effect of stress-releasing time, the design stress is suggested below fracture initiation (B) in geomaterials. Relevant in-situ monitoring in structures is recommended for the allowable design stress ranging around fracture initiation (B).

\section{CONCLUSIONS}

Acoustic emission signals are highly associated with microcracking in stressed modeling geomaterials. Based on the AE experimental results of microcracking and stress-releasing time in modeling geomaterials, several conclusions can be drawn:
1. Two different AE characteristics are found in the stressed modeling materials during stable fracture propagation stage (BC). An accelerative cracking point $(\lambda)$ is introduced at stable fracture propagation stage $(\mathrm{BC})$. The point is the turning point of the crack growth velocity changing from a gradual increase state into a steep increase state. The stable fracture propagation stage (BC) is divided into the mild stable fracture propagation former section $(B \lambda)$ and steep stable fracture propagation later section $(\lambda \mathrm{C})$.

2. Under the previous maximum stress level at stable fracture propagation former section $(\mathrm{B} \lambda)$, the measured macromechanical response is consistent with its microcracking behavior, $\mathrm{AE}$ activity. A higher $\mathrm{AE}$ hit rate occurs at the loading stage. Increasing the number of loading cycle aggravates the internal damage by observing the occurrence of the highest AE hit rate at the peak stress. These minor $\mathrm{AE}$ signals reveal that some internal changes really occur, but not are detected by strain measurement. The conventional mechanical experimental results can represent the real mechanical characteristics in materials.

3 . Under the previous maximum stress level during the stable fracture propagation later section $(\lambda C)$, continuously increasing AE activity with the increase of cyclic number indicates that microcracking is no longer controlled by its stress level. The highest AE hit rate occurs around the unloading stage and significant AE signals with middle-tohigh energy level are detected at crack closure stage (OA). $\mathrm{AE}$ activity provides critical inner changes similar to the non-stress-controlled facture occurring at unstable fracture propagation. The conventional mechanical experimental results cannot represent the real mechanical characteristics in materials.

4. Allowable design stresses are suggested below the accelerative cracking point $(\lambda)$, not the critical energy release point $(C)$ for preventing from over-estimating the design strength in geomaterials based on the conventional mechanical experimental results.

5. For the previous maximum stress level equal to or more than fracture initiation (B), the onset stress level of $\mathrm{AE}$ signals lower than the previous maximum stress level indicates the inefficacy with Kaiser effect. The onset stress level of AE signals decreases as stress-releasing time becomes longer.

6. Long-term allowable design strengths are recommended below fracture initiation (B) to prevent from the effect of stress-releasing time in geomaterials. An in-situ monitoring in structures is recommended for the allowable design stress ranging around the fracture initiation (B).

\section{REFERENCES}

1. American Society for Testing and Materials, "ASTM C192-90a standard practice for making and curing concrete test specimens in the laboratory," in Annual Book of ASTM Standard 2000, Section Four: Construction, Vol. 04.02, Concrete and Aggregates, ASTM International, West Conshohocken, PA, U.S.A., pp. 183-189 (2000). 
2. Bieniawaki, Z. T., "Mechanism of brittle fracture of rock, Parts I, II, III," International Journal of Rock Mechanics and Mining Sciences and Geomechanics Abstracts, Vol. 4, No. 4, pp. 395-430 (1967).

3. Bieniawaki, Z. T., Franklin, J. A., Bernede, M. J., Duffaut, P., Rummel, F., Horibe, T., Broch, E., Rodrigues, E., Van Heerden, W. L., Vogler, U. W., Hansagi, I., Szlavin, J., Brady, B. T., Deere, D. U., Hawkes, I., and Milovanovic, D., "Suggested methods for determining the uniaxial compressive strength and deformability of rock materials," in: Brown, E. T. (Ed.), Rock Characterization Testing and Monitoring, International Society for Rock Mechanics Suggested Methods, Pergamon Press, Oxford, U.K., pp. 111-116 (1981).

4. Boyce, G. M., McCabe, W. M., and Koerner, R. M., "Acoustic emission signatures of various rock types in unconfined compression," in: Drenvich, V. P. and Gray, R. E. (Eds.), Acoustic Emissions in Geotechnical Engineering Practice, ASTM STP 750, American Society for Testing and Materials (ASTM), West Conshohocken, PA, U.S.A., pp. 142-154 (1981).

5. Cai, M. and Kaiser, P. K., "Assessment of excavation damaged zone using a micromechanics model," Tunnelling and Underground Space Technology, Vol. 20, No. 4, pp. 301-310 (2005).

6. Cai, M., Morioka, H., Kaiser, P. K., Tasaka, Y., Kurose, H., Minami, M., and Maejima, T., "Back-analysis of rock mass strength parameters using AE monitoring data," International Journal of Rock Mechanics and Mining Sciences, Vol. 44, No. 4, pp. 538-549 (2007).

7. Costin, L. S., "Time-dependent deformation and failure," in: Atkinson, B. K. (Ed.), Fracture Mechanics of Rock, Academic Press Inc. Ltd., London, U.K., pp. 167-215 (1987).

8. Cox, S. J. D. and Meredith, P. G., "Microcrack formation and material softening in rock measured by monitoring acoustic emissions," International Journal of Rock Mechanics and Mining Sciences and Geomechanics Abstracts, Vol. 30, No. 1, pp. 11-24 (1993).

9. Dugat, J., Roux, N., and Bernier, G., "Mechanical properties of reactive powder concretes," Materials and Structures, Vol. 29, No. 5, pp. 233-240 (1996).

10. Elaqra, H., Godin, N., Peix, G., R'Mili, M., and Fantozzi, G., "Damage evolution analysis in mortar, during compressive loading using acoustic emission and X-ray tomography: Effects of the sand/cement ratio," Cement and Concrete Research, Vol. 37, No. 4, pp. 703-713 (2007).

11. Filimonov, Y. L., Lavrov, A. V., Shafarenko, Y. M., and Shkuratnik, V. L., "Memory effects in rock salt under triaxial stress state and their use for stress measurement in a rock mass," Rock Mechanics and Rock Engineering, Vol. 34, No. 4, pp. 275-291 (2001).

12. Friedel, M. J. and Thill, R. E., "U.S. bereau of mines research on the Kaiser effect for determining stress in rock," Journal of Acoustic Emission, Vol. 10, Nos. 1/2, pp. s77-s89 (1991/1992).

13. Gere, J. M. and Timoshenko, S. P., Mechanics of Materials, $4^{\text {th }}$ edition, PWS-KENT Publishing Company, Boston, MA, U.S.A. (1998).

14. Goodman, R. E., "Subaudible noise during compression of rock," Geological Society of America Bulletin, Vol. 74, pp. 487-490 (1963).

15. Goodman, R. E., Introduction to Rock Mechanics, $2^{\text {nd }}$ Edition, John Wiley and Sons, Inc., New York, NY, U.S.A. (1989).

16. Haimson, B. C., "Effect of cyclic loading on rock," in: Wheeler, J. B., Hoersch, H. M., McGlinchey, E. J., and Mahy, H. (Eds.), Dynamic Geotechnical Testing, ASTM STP 654, American Society for Testing and Materials (ASTM), West Conshohocken, PA, U.S.A., pp. 228-245 (1978).

17. Hardy, H. R., Zhang, D., and Zelanko, J. C., "Recent studies of the Kaiser effect in geologic materials," Proceedings of the $4^{\text {th }}$ Conference on Acoustic Emission/Microseismic Activity in Geologic Structures and Materials, University Park, PA, U.S.A., pp. 27-56 (1989).

18. Hayashi, M., "Acoustic emission to detect the geostress," Proceedings of the $4^{\text {th }}$ International Congress on Rock Mechanics, Montreux, Switzerland, Vol. 2, pp. 230-231 (1979).

19. Holcomb, D. J., "Memory, relaxation, and microfracturing in dilatant rock," Journal of Geophysical Research, Vol. 86, No. B7, pp. 6235-6248 (1981).

20. Holcomb, D. J. and Costin, L. S., "Damage in brittle materials: Experimental methods," Proceedings of the $10^{\text {th }}$ U.S. National Congress of Applied Mechanics, Austin, TX, U.S.A., pp. 107-113 (1986).

21. Hung, J.-J., Outline of Preliminary Engineering Geology, $1^{\text {st }}$ edition,
Sino-Geotechnique Research and Development Foundation, Taipei, Taiwan (1991).

22. Kanagawa, T., Hayashi, M., and Nakasa, H., "Estimation of spatial geo-stress compression in rock samples using the Kaiser effect of acoustic emission," Proceedings of the $3^{\text {rd }}$ Acoustic Emission Symposium, Tokyo, Japan, pp. 229-248 (1976).

23. Kurita, K. and Fujii, N., "Stress memory of crystalline rocks in acoustic emission," Geophysical Research Letters, Vol. 6, No. 1, pp. 9-12 (1979).

24. Lavrov, A., "The Kaiser effect in rocks: Principles and stress estimation techniques," International Journal of Rock Mechanics and Mining Sciences, Vol. 40, No. 2, pp. 151-171 (2003).

25. Li, C. and Nordlund, E., "Assessment of damage in rock using the Kaiser effect of acoustic emission," International Journal of Rock Mechanics and Mining Sciences and Geomechanics Abstracts, Vol. 30, No. 7, pp. $943-$ 946 (1993).

26. Li, C. and Norlund, E., "Experimental verification of the Kaiser effect in rocks," Rock Mechanics and Rock Engineering, Vol. 26, No. 4, pp. 333-351 (1993).

27. Lin, H.-H., The Influence of Horizontal Joints on the Uniaxial Compression Strength of Rock Masses, Master Thesis, Graduate Institute of Civil Engineering, National Taiwan University, Taipei, Taiwan (1993).

28. Mehta, P. K. and Monteiro, P. J. M., Concrete: Structures, Properties, and Materials, $2^{\text {nd }}$ edition, Prentice Hall, Englewood Cliffs, NJ, U.S.A. (1993).

29. Michihiro, K., Fujiwara, T., and Yoshioka, H., "Study on estimating geostress by the Kaiser effect of AE," Research and Engineering Application in Rock Mechanics, Proceedings of the $26^{\text {th }}$ U.S. Symposium on Rock Mechanics, Rapid City, SD, U.S.A., pp. 557-564 (1985).

30. Michihiro, K., Hata, K., Fujiwara, T., Yoshioka, H., and Tanimoto, T., "Study on estimating initial stress and predicting failure on rock masses by acoustic emission," Rock at Great Depth, Rock Mechanics and Rock Physics at Great Depth, Proceedings of ISRM/SPE International Symposium, Pau, France, Vol. 2, pp. 1025-1032 (1989).

31. Michihiro, K., Hata, K., Yoshioka, H., and Fujiwara, T., "Determination of the initial stresses on rock mass using acoustic emission method," Journal of Acoustic Emission, Vol. 10, Nos. 1/2, pp. s63-s76 (1991/1992).

32. Mindess, S., "Acoustic emission method," in: Malhotra, V. M. and Carino, N. J. (Eds.), Handbook on Nondestructive Testing of Concrete, CRC Press, Boca Raton, FL, U.S.A., pp. 14-1-14-19 (2004).

33. Momayez, M. and Hassani, F. P., "Application of Kaiser effect to measure in-situ stresses in underground mines," Rock Mechanics, Proceedings of the $32^{\text {nd }}$ U.S. Symposium on Rock Mechanics, Norman, OK, U.S.A., pp. 979-988 (1992).

34. Paterson, M. S., Experimental Rock Deformation- The Brittle Field, Springer-Verlag, Berlin, Germany (1978).

35. Rao, M. V. M. S., "A study of acoustic emission in granites during stress cycling experiments," Journal of Acoustic Emission, Vol. 7, No. 3, pp. s29-s34 (1988).

36. Rao, M. V. M. S. and Ramana, Y. V., "A study of progressive failure of rock under cycling loading by ultrasonic and AE monitoring techniques," Rock Mechanics and Rock Engineering, Vol. 25, No. 4, pp. 237-251 (1992).

37. Richard, P. and Cheyrezy, M., "Reactive powder concretes with high ductility and 200-800 MPa compressive strength," ACI Spring Convention, San Francisco, CA, U.S.A. (1994).

38. Scholz, C. H. and Kranz, R., "Notes on dilatancy recovery," Journal of Geophysical Research, Vol. 79, No. 14, pp. 2132-2135 (1979).

39. Shi, L.-P., "A Study of Rockburst During Underground Excavation at High In-Situ Stress State Condition, Ph.D. Dissertation, Graduate Institute of Civil Engineering, National Taiwan University, Taipei, Taiwan (1996).

40. Sondergeld, C. H. and Estey, L. H., "Acoustic emission study of microfracturing during the cycling loading of Westerly granite," Journal of Geophysical Research, Vol. 86, No. B4, pp. 2915-2924 (1981).

41. Tsai, H.-M., A Study on Acoustic Emission and Permeation in Rocks, Master Thesis, Graduate Institute of Civil Engineering, National ChengKung University, Tainan, Taiwan (1991).

42. Watanabe, T., Nishibata, S., Hashimoto, C., and Ohtsu, M., "Compressive failure in concrete of recycled aggregate by acoustic emission," Construction and Building Materials, Vol. 21, No. 3, pp. 470-476 (2007). 